\title{
First, Second and Third Person in the Emergence of Thought
}

\author{
MiguEL ÁNGEL PÉREZ JIMÉNEZ
}

\begin{abstract}
What does it mean to say that thought has social basis? This paper deals with this issue taking into account Davidson's views on radical translation. In our view, they constitute a plausible model to explain the social basis of thought. Nevertheless, the task demands precisions about the aims and some methodological aspects of that philosophical project. Wittgenstein's remarks on mutual understanding will help us to precise the misleading aspects of radical translation. The text has three sections. First, we show that radical translation is a version of a phenomenological Leitmotiv. We raise our discussion deploying the first/third person dichotomy. Secondly, we show that radical translation is improved and corrected by Wittgenstein's remarks on mutual understanding. This leads us to describe a non-interpretive social interaction as the ground of thought. We call this kind of interaction 'the second person perspective'. Thirdly, we give some reasons for saying that emotivity is the specific feature of the second person ${ }^{1}$. Our thesis is that an emotive non-conceptual interaction is the social grounding of the emergence of thought.
\end{abstract}

\section{First and Third Person in the Emergence of Thought}

Philosophers from different traditions consider as irrelevant the issue of the emergence of thought. ${ }^{2}$ There is a phenomenological Leitmotiv behind those positions: we always interpret from a conceptual frame of reference and there is no way out of there. The argument for the triviality of inquiring the emergence of thought goes like this: first, we cannot abandon our own conceptions when we are to understand others'. Second, our own positions

\footnotetext{
${ }^{1}$ This paper was written during a scholarship in Granada University, Spain, sponsored by Pontificia Universidad Javeriana, Bogotá, Colombia, LASPAU and Colciencias.

${ }^{2}$ Gadamer 1972, 448; Davidson 1997, 128.
}

Phenomenology as Grammar (Ed. Jesús Padilla Gálvez), 185-197.

(C) Ontos Verlag, Frankfurt a. $M$. 
are always conceptual. Then, third, the approach to non-conceptual realities, qua non-conceptual, is impossible. The task of theorizing about how a nonconceptual creature develops into a conceptual one becomes absurd.

The phenomenological Leitmotiv acknowledges the always-located position of thought. Nevertheless, if we accept it, we can also ask how to open a place for strangers within our own position? In this respect, it is common to say that dialogue is the way we have to open a place for strangers. In this sense, dialogue is often described as fusion of horizons that occurs in 'the meddle of language'. ${ }^{3}$ This means that interpreter and speaker are linguistic and cognitive beings. If that is correct, the phenomenological Leitmotiv carries an intrinsic circularity: its mark is a conceptual confinement. This conceptual enclosure has motivated the trivialization of the question for the emergence of thought.

Radical translation is a version of the phenomenological Leitmotiv. Paradoxically, its basic aim as a philosophical project was to break out the conceptual confinement, as we will see. In Glock's terms, "Radical Translation" is the kind of situation where we try to understand conceptual frames different from our own. ${ }^{4}$ However, differences intended in that philosophical project appear between the speaker's propositional attitudes and the interpreter's ones. They both are always the same in their anthropological condition. Because of this radical translation can never go out of the conceptual enclosure. Let us see some more details.

Radical translation affirms that we use one of two types of vocabulary in interpretation: intensional or extensional. We describe intensionally all thinking creatures, and we describe extensionally all the rest of beings. We lack of a good vocabulary for intermediate stages. ${ }^{5}$ The plausibility of this position is clear if we consider that, on one hand, interpretation of non-

\footnotetext{
${ }^{3}$ Gadamer 1972, 366. We assume an interdependence relation between language and thought as illustrated in Davidson 1975, 1982.

${ }^{4}$ Glock 1996a, 144, n1. The term 'radical translation' was introduced by Quine 1960, 26ff. in the development of a semantic theory, and it was adapted as 'radical interpretation' to interpretive situations by Davidson 1973. Glock 1996a backs to 'radical translation' but modifies its meaning to make use of Wittgenstein's thoughts in relation to Quine's and Davidson's theories locating all those reflections in the field of philosophical anthropology.

${ }^{5}$ Davidson 1997, 128.
} 
conceptual creatures does not require psychological vocabulary. We explain animal and mechanical behavior by means of extensional and causal terms. In this case, we do not need to ascribe normative standards neither the postulation of beliefs nor evaluative attitudes. On the other hand, interpretation of persons requires attribution of different kinds of propositional attitudes using psuchological terms. Furthermore, those attitudes must be coherent among themselves according to a normative pattern that, following the Principle of Charity, is the very same of the attributer. $^{6}$

This argument helps us to state the problem of the emergence of thought as follows. We call 'first person' the perspective of the interpreter that projects its own conceptions on the interpreted using an intensional and normative vocabulary. We call 'third person' the scientific and nomological perspective that employs an extensional vocabulary. The first person perspective is egocentric and normative. The third person one is impersonal and nomological. It follows that those perspectives become incompatible in the question for the emergence of thought. When a creature is pre-conceptual, it is interpreted nomologically, but when it is a developed one, it is interpreted normatively. In the stages of the emergence of thought, the creature is normative and non-normative at the same time, or it is neither one nor another.

Some specialists have shown the striking feature that the first/third person dichotomy gives to the emergence of thought problem. They have also claimed a 'second person' approach as a solution for the tension. ${ }^{7}$ In our view, the problem they have shown is that the sources of normativity are obscur. The argument is that if the third person perspective cannot explain the sources of normativity, the first person one must explain this. However, the first person explanation leads us to the conceptual confinement of the phenomenological Leitmotiv where the problem cannot be raised.

Following those ideas, it is common to say that 'first person' vanishes into an intersubjective constitution. Attitud attribution projects the tradition, the culture or the form of life of the interpreter, not her or his individuality. For that reason, it is common to say that thought has social basis. Indeed,

\footnotetext{
${ }^{6}$ Davidson 1991, 210f.

${ }^{7}$ Miguens 2006, 113; Pinedo 2004, 228.
} 
several philosophical and psychological recent works ${ }^{8}$ have claimed that it is a necessary condition of thought some kind of interaction with thinking creatures. It is necessary some social interaction with thinking beings to become a creature whose mental states have definite propositional content. ${ }^{9}$ However, what is the others human beings' role in the emergence of thought? How do they do their job? It is not enough to say that thought has social basis, this is not an answer to those questions. Nevertheless, some answer must be given if it makes sense to say that thought has social basis.

\section{The Second Person in the Emergence of Thought}

Radical translation was intended as a philosophical project to face the circularity problem of intensional notions. Its aim was to show how the intensional could be derived from the extensional. Explaining the conditions of that derivation is the only way to break up the intensional circularity. ${ }^{10}$ For this reason, we should say, radical translation seems to be a good strategy to inquire the emergence of thought. Nevertheless, that philosophical project is a version the phenomenological Leitmotiv, as we saw. What can we do with this paradoxical situation? Where are its roots?

Radical translation theoreticians drew homophonic and heterophonic interpretive situations as methodological scenarios for their inquiry. Nevertheless, those situations do not fit well with the aims of their project. The inadequacy of aim and methodological strategy appears because creatures involved in those scenarios share their anthropological condition. Interpreter and interpreted are thinking and linguistic creatures. Any other kind of being outside interpretation must be treated as a non-conceptual one. In this respect, a baby and a snail are the very same kind of creatures! $!^{11}$ This is a mistake.

\footnotetext{
${ }^{8}$ See Campbell 1998, 124ff; Eilan et al. 2005.

${ }^{9}$ Intersubjectivity is not the only condition of thought, because it is also necessary the existence of an objective world to causally fix propositional contents. The objectivity of thought depends on this causal origin. We do not take into account the influence of the world in thought because we are examining the problem of the social basis of thought, not its objectivity. The most comprehensive schema for intersubjectivity and objectivity of thought is Davidson's triangulation (Davidson 1997, 128ff.; Davidson 2001a).

${ }^{10}$ Heal 1997, 176; Ramberg 1989, 71.

11 Davidson 1982, 95.
} 
Ex hipotesi, we will not accept that all non interpretive creatures are non-conceptual. Therefore, we introduce a distinction between nonconceptual and pre-conceptual creatures. These two types of beings cannot be taken in the same way in interpretive situations. Thus, let us call transitional triangulation the new interpretive situation involving the interaction among one conceptual creature, one pre-conceptual creature and an objective situation. In our view, transitional triangulation is an adequate scenario to raise the question for the emergence of thought in the context of radical translation. ${ }^{12}$

Transitional triangulation differs from classical radical translation scenarios and from classical triangulation too. In these classical scenarios, the interpreter takes both the linguistic behavior of the speaker and the environment conditions as evidence for content attribution. In transitional triangulation, the interpreter does not have behavioral linguistic evidence to support his thoughts ascription. Babies do not speak, so the interpreter lacks of evidence. He has not proper conceptual tools to relate baby's behaviour to specific features of the environment. Baby's behavior is not complex enough for the interpreter if he is to attribute definite propositional contents to it. Moreover, whithout propositional attitudes attribution, the interpreter lacks of criteria for evaluating the coherence of the baby's mental states. That is why it is not proper to fix "baby's actions" in rationality standards by means of the Principle of Charity. ${ }^{13}$

The problem is that charity is not an option. Interpreters in fact ascribe thoughts to babies. Interpreters project their own thoughts to them! Now the question is: how can an interpreter ascribe normative mental states to a creature when he never ascribed this kind of states to the same creature before? Is this an arbitrary attribution? Could that be an evidence-based attribution? What is the evidence the interpreter use to make her improper attribution of normative mental states to pre-conceptual creatures in transitional triangulations scenarios?

\footnotetext{
12 The concept of 'triangulation' was introduced in the philosophy of language and mind by Davidson 1982, 105. He recognizes two types of triangulation, depending on the kind of agents involved, they could be both conceptual or both non-conceptual. When the creatures are both conceptual, triangulation is the same as the homophonic or heterophonic scenarios of radical translation. (Davidson 2001b, 294).

${ }^{13}$ Davidson 1997, 130f.
} 
These questions lead us to a situation similar to the indeterminacy of interpretation: every set of evidence fits well many different thought attributions. The problem also reminds the classical wittgensteinian paradox: "one rule cannot determine one action, because every action could fit well the rule". ${ }^{14}$ Some proposals about the paradox show interesting conclusions that will help us to shed light on the social basis of thought.

The "following a rule paradox" was the source of some kind of skepticism in the theory of meaning. If we cannot say what is an adequate rule, and if language is a rule-based activity, then we can never say what the meaning of an expression is. Nevertheless, the skeptical interpretation forgets that there is a non-interpretive way of following the rule, despite the many different interpretations we can make of the rule. This non-interpretive following is signed by the use of normative expressions like "this is the correct following of the rule" or "that contravenes the rule". 15

That normative solution to the paradox has motivated conventionalist interpretations of the sources of normativity. What defines the correct rulefollowing is a social convention. The interpreter determines what is correct in every case, and he expresses the point of view of its own community. Certain following of the rule is said correct because of its fitting with a background named 'tradition', 'culture', 'society' or 'form of life'. If the following of the rule fits the background, it is correct; if it does not, is incorrect. ${ }^{16}$

There are, at least, two senses in which this conventionalist approach to normativity is misleading. First, what matters in thought's normativity determination is the use we make of rules' formulation, not its social character. ${ }^{17}$ Second, by definition nothing previous defines the meaningfulness or the normativity of thought. The mark of an interpreter is his capacity to understand and produce meaningful expressions that he has never heard before. ${ }^{18}$

If that is correct, conventionalism is not a plausible solution to the sources of normativity problem. Nevertheless, the discussion helps us to say

\footnotetext{
${ }^{14}$ Wittgenstein $P U, 1953$, §201; Davidson 1992, 116; Glock 1996a, 162f.

${ }^{15}$ Glock 1996b, 327.

${ }^{16}$ Glock 1996b, 327.

${ }^{17}$ Glock 1996a, 165.

${ }^{18}$ Davidson 1992, 111.
} 
something in the right direction to solve the problem. On one hand, we leave skepticism because there is a non-interpretive use of the rule. There is some kind of non-interpretive behavior that we call the correct following the rule. On the other hand, we abandon conventionalism because what defines normatvity is some kind of social interaction that allows or refuses future interactions. What kind of non-interpretive interaction is the base of normativity?

It is often said that communicative linguistic interaction is the base of normativity. However, in transitional triangulation scenarios we cannot take in advance the semantic content of orders, petitions, exclamations and other communicative means as resource to establish normativity. We cannot communicate our beliefs and our desires to baby because it cannot understand its propositional content. On the contrary, we can show it what we want and what we believe by means of behavioral features that it "understands" and that we know it understands. Wittgenstein has shown that the possibility of this non-linguistic mutual understanding lies in some capacities for recognizing behavioral features like gestures, mannerisms, facial expressions or voice intonation. Indeed, these modalities of action are fundamental ingredients in the general mutual understanding, including linguistic understanding too. ${ }^{19}$

On line with Wittgenstein's remarks, theoreticians of joint attention have shown that the absence of gesture interaction bears important distortions in cognitive and relational functions, that in many cases bring up to autism. ${ }^{20}$ The argument is that at the early stages of development, between the first and second year of life, triangulations take place in dyadic interactions, babynanny, from the interpreters point view. Triangle's third element, the object attended by baby and nanny, emerges later. ${ }^{21}$ Using its non-conceptual abilities for gesture recognition, the baby recognizes itself as a part of nanny's activity. For the baby to recognize its place in the triangle it must be involved

\footnotetext{
${ }^{19}$ Wittgenstein $P U, 1953, \S 54$; Glock 1996, 167.

${ }^{20}$ Joint attention is a psychological phenomenon similar, but not identical, to Davidson's triangulations. Joint attention deploys the concept of 'attention' instead of Davidson's concept of 'recognition'. Triangulation is described as two creatures attending mutually to an object and they know that the other respective creature is paying attention to the same object. (Eilan 2005, 4f.)

${ }^{21}$ Hobson 2005, 188; Reddy 2005, 88.
} 
in nanny's activities. In this dyadic interaction, baby-nanny, it finds her gestures like answers to an external object: itself. ${ }^{22}$ For this reasons gesturebased interaction is a necessary condition of the ideas of an external world and of "I in relation to the other".

Thus, the social interaction grounding thought is the encounter neither of two traditions nor of two first persons. Furthermore, it cannot be called 'third person' because it is not conceptual. We can say then that it is some kind of non-conceptual interaction, a gesture-based one. It could be described like a thou-thou interaction. Nanny behaves like a thou for the baby, and treats the baby like a thou for herself. We will call this kind of interaction 'the second person perspective'. If this mutual treatment is a gesture-based interaction, then the essential feature of the second person perspective is that it is a non-conceptual interaction grounded on gesture production and gesture recognition abilities.

\section{The Idea of an Emotional Second Person}

We have highlighted two features of thought: its intersubjective source and its normativity. If the second person perspective is the base of thought, we must explain how the mutual encounter of thous does occur and how the mutuality becomes the source of thought's normativity. Although we cannot offer a detailed explanation of these issues, we could offer reasons for the idea that describing the second person as an emotional one shed light to understand them.

An approach to mutuality in the light of the second person perspective requires a distinctive understanding of mind. We must abandon the dilemma between reductionist positions, which identifies mind with behavior, and nonreductionist ones, which divorce one from the other. The former gives priority to the third person perspective, the latter to the first one. Thus, we must find a different understanding of mind adequate for the second person perspective. ${ }^{23}$

Psychological studies of attention show emotions as a mental phenomena which permits the "souls communion" by means of its

\footnotetext{
${ }^{22}$ Reddy 2005, 86.

${ }^{23}$ Reddy 2005, 92.
} 
manifestation in actions. ${ }^{24}$ With Wittgenstein, the gesture component is not intrinsic to actions but some kind of qualification of them, a modality of actions. ${ }^{25}$ This kind of qualitative variation of actions occurs paradigmatically when the agent is in a relevant emotional state. Those modalities are often explained by the existence of 'affect programs'. Affect programs are some biological stuff that makes people sweat, change the voice intonation and so on, in a specific situation. Affect programs hypothesis describes emotions in a distinctive way different from the behavior and from the cause of the behavior. Emotions are part of the behavior, they are modalities of action.

Therefore, two aspects of emotions make them good candidates to fulfill the content of 'second person' notion from the perspective of the mutuality problem. First: affect programs are capacities for producing behavioral qualification and for recognition of behavior's emotional features. Then, the affect programs hypothesis is a good way to understand how the mutuality begins. ${ }^{26}$ Second: emotions are not actions but modalities of actions. Then, they are some way independent of the propositional contents we use to interpret actions. Nevertheless, emotions are compatibles with intensional interpretations of action too. Because of this, they become helpful to explore mental aspects from both conceptual and non-conceptual points of view. ${ }^{27}$ This idea is expressed as affective primacy thesis: emotional responses are independent of the rational evaluations we make of situations. ${ }^{28}$ Thus, emotions are good candidates to give some content to idea of a second person. Nevertheless, such thesis will be more plausible if it also explains the sources of tohught's normativity.

Recent studies on attention have recognized the value of emotions to explain some features of infant behavior: pointing gesture and gaze following. It is common to describe these actions like a primitive form of object and person manipulation based on a means-ends proto-reasoning. ${ }^{29}$ This description is not too convincing because we only ascribe this kind of reasoning to developed creatures, not to two-year-old babies! In this context,

\footnotetext{
${ }^{24}$ Hobson 2005, 186.

${ }^{25}$ Pickard 2003, 93; Glock 1996a, 168.

${ }^{26}$ Griffiths 2003, 42; Pickard 2003, 93; Wittgenstein RPP, 1980, 570.

${ }^{27}$ Reddy 2005, 97.

${ }^{28}$ Griffiths 2003, 43.

${ }^{29}$ Franco 2005, 145.
} 
emotions appear like better candidates to explain gaze following and pointing gestures as used by babies.

According to Machiavellian Emotion Hypothesis, emotional agents perceive features that facilitate the social interaction. That perception deploys the recognitional aspect of affect programs. The perceived creature manifests its emotions by the productive aspect of affect programs. ${ }^{30}$ Perceived features cause the emotional response of the interpreter, and then become the individuation criteria for emotions. Each situation determines the specific response by means of environment features that the agent perceives like more or less suitable for interaction.

In the case of baby's emotional responses, manipulation is directed to call nanny's attention or to get objects. However, in adults' case manipulation is a little bit different. An adult can react emotionally to a baby's emotionally qualified action, like pointing to an object with a smiling face for example. Adult's reaction can include emotional gestures or emotionally qualified actions to modify baby's behavior. Adults can pick the object up to baby making smiling faces, and using warm voice tones, but they can also react with facial expressions of surprise and saying: "don't do that!" This response and some other mannerisms stop baby's gesture when it is to take off his grandpa's glasses, for instance. Approving and refusing gestures, based on emotional features, have made to think that emotional interaction is a strategy human beings use to introduce children into their forms of life. ${ }^{31}$

But emotional transactions are not emotional behaviorism, as it has been shown by studies with apes. Scientists tell us that apes prefer making emotional gestures to find food, although in the end they were not fed, when their requirements are denied accompanied with emotional gestures. ${ }^{32}$ Contrary to reflex impulses, emotional responses can modify the behavior in a non-mechanical way. That is the reason why by them we can introduce babies into normative forms of behavior where some values are preferred over others. For this reason, emotional interaction opens an adequate space to use

\footnotetext{
${ }^{30}$ Griffiths 2003, 50.

${ }^{31}$ Goldie 2003, 212.

${ }^{32}$ Gómez 2004, $257 f$.
} 
expressions like "this is a correct following of a rule" or "that contravenes the rule". 33

The general image of the emotional second person is the following. Taking advantage of a biological stuff, affect programs, babies and adults recognize pleasant and avoiding gestures directed to their own actions. Emotional responses, although automatic, are not predetermined because they are individuated by the complex situation of the emotional exchange. Emotional interaction occurs in order to get some objectives by interacting creatures. Thanks to this feature, adults manipulate baby's behavior in various ways to make it share values, attitudes and kinds of actions characteristic of their form of life. For that reason baby also can learn the values, attitudes and kinds of actions adults teach it. Far away from an emotional behaviorism, the emotional second person is an explicative model of the introduction into a form of life that exhibits at least two characteristic features of thought: social basis and normativity.

With Glock, ${ }^{34}$ Wittgenstein's remarks improve and correct radical translation. Against Glock, ${ }^{35}$ if we precise the aims and methods of this philosophical project, it could be considered as a plausible program to face the emergence of thought problem. The aim will not be derive the intensional from the extensional, as claimed by Davidson. The objective could be to disclose the necessary non-conceptual elements for the emergence of thought. One of those non-conceptual elements could be the emotional interaction characteristic of the second person perspective.

\section{References}

Campbell, J. 1998: Joint Attention and the First Person, in: Anthony O'Hare, (ed.), Current Issues in the Philosophy of Mind, Cambridge University Press, Cambridge, 123-136.

Davidson, D. 1975: Thought and Talk, in: Inquiries into truth and Interpretation, Clarendon Press, Oxford, 20012, $155-170$.

\footnotetext{
${ }^{33}$ Reddy 2005, 97.

${ }^{34}$ Glock 1996a, 168.

${ }^{35}$ Glock 2003, 262f.
} 
Davidson, D. 1982: Rational Animals, in: Subjective, Intersubjective, Objective, Clarendon Press, Oxford, 2001, 95-105.

Davidson, D. 1991: Three Varieties of Knowledge, in: Subjective, Intersubjective, Objective, Clarendon Press, Oxford, 2001, 205-220.

Davidson, D. 1992: The Second Person, in: Subjective, Intersubjective, Objective, Clarendon Press, Oxford, 2001, 107-121.

Davidson, D. 1997a: The Emergence of Thought, in: Subjective, Intersubjective, Objective, Clarendon Press, Oxford, 2001, 122-134.

Davidson, D. 2001a: Externalisms, in: Peter Kotatko et al. (eds.), Interpreting Davidson, CSLI, Stanford, 1-16.

Davidson, D. 2001b: Comments on Karlovy Vary Papers. in: Peter Kotatko et al. (eds.), Interpreting Davidson, CSLI, Stanford, 285-307.

Eilan, N. 2005: Joint Attention, Comunication and Mind, in: Naomi Eilan et al. (eds.), Joint Attention: Communication and Other Minds, Oxford University Press, Oxford, 1-33.

Franco, F. 2005: Infant Pointing: Harlequin, Servant of Two Masters, in: Naomi Eilan et al. (eds.), Joint Attention: Communication and Other Minds, Oxford University Press, Oxford, 129-164.

Gadamer, H. 1972: Wahrheit und Methode, J. C. B. Mohr, Tübingen.

Glock, H. 1996a: On Safari with Wittgenstein, Quine and Davidson, in: Robert Arrington et al. (eds.), Wittgenstein and Quine, Routledge, London, 144-172.

Glock, H. 1996b: A Wittgenstein's Dictionary, Blackwell, Oxford.

Glock, H. 2003: Quine and Davidson on Language Thought and Reality, Cambridge University Press, Cambridge.

Goldie, P. 2003: Narrative and Perspective; Values and Appropiate Emotions, in: Anthony Hatzimoysis (ed.), Philosophy and the Emotions, Cambridge University Press, Cambridge, 201-220.

Gómez, J. 2004: El desarrollo de la mente en los simios, los monos y los niños, Morata, Madrid.

Gómez, J. 2005: Joint Attention and the Notion of Subject: Insights from Apes, Normal Children, and Children with Autism, in: Naomi Eilan et al. (eds.), Joint Attention: Communication and Other Minds, Oxford University Press, Oxford, 65-84.

Griffiths, P. 2003: Basic Emotions, Complex Emotions, Machiavelian Emotions, in: Anthony Hatzimoysis (ed.), Philosophy and the Emotions, Cambridge University Press, Cambridge, 39-67. 
Heal, J. 1997: Radical Interpretation, in: Bob Hale et al. (eds.), A Companion to the Philosophy of Language, Blackwell, Oxford, 175-196.

Hobson, P. 2005: What Puts the Jointness into Joint Attention, in: Naomi Eilan et al. (eds.), Joint Attention: Communication and Other Minds, Oxford University Press, Oxford, 185-204.

Miguens, S. 2006: Conceito de crença, trianulações e atencão conjunta, in: Perspectives on Rationality, Faculdade de Letras da Universidade do Porto, Porto, 99-117.

Pickard, H. 2003: Emotions and the Problem of Other Minds, in: Anthony Hatzimoysis (ed.), Philosophy and the Emotions, Cambridge University Press, Cambridge, 87103.

Pinedo, M. 2004: De la interpretación radical a la fusión de horizontes: la perspectiva de la segunda persona, in: Juan José Acero et al. (eds.), El legado de Gadamer, Universidad de Granada, Granada, 225-235.

Quine, W. 1960: Word and Object, The MIT Press, Harvard.

Ramberg, B. 1989: Donald Davidson's Philosophy of Language, Blackwell, Oxford.

Reddy, V. 2005: Before the 'Third Element': Understanding Attention to Self, in: Naomi Eilan et al. (eds.), Joint Attention: Communication and Other Minds, Oxford University Press, Oxford, 85-109.

Wittgenstein, L. 1953: Philosophical Investigations, Blackwell, Oxford.

Wittgenstein, L. 1980: Remarks on the Philosophy of Psychology II, Blackwell, Oxford. 
